\title{
O PESO DO TRABALHO "LEVE" FEMININO À SAÚDE
}

\author{
Willer Baumgartem Marcondes \\ Lúcia Rotenberg \\ Luciana Fernandes Portela \\ Claudia Roberta de Castro Moreno
}

\begin{abstract}
Resumo: Valendo-se de estudo empírico com trabalhadores(as) do turno noturno, irá se discutir divisão sexual do trabalho, qualificação profissional, trabalho doméstico, trabalhos "pesados" e "leves" e suas possíveis repercussões diferenciadas à saúde de homens e mulheres. Gênero e trabalho lançam luzes um sobre o outro e revelam aspectos em que a produção e a reprodução imbricam-se, apontando para a desconstrução de estereótipos. Palavras-chave: divisão sexual do trabalho; saúde; trabalho noturno.
\end{abstract}

\begin{abstract}
Based on an empirical study of night-shift workers, this article discusses the gender division of labor, professional qualifications, domestic work, "heavy" and "light" work, and the possible repercussions on the health of men and women. The terms "gender" and "labor" are mutually revealing, unveiling aspects in which production and reproduction are tied into one another, suggesting a deconstruction of stereotypes. Key words: gender division of labor; health; night shift.
\end{abstract}

$\mathrm{E}$ ste artigo baseia-se na pesquisa Gênero e Trabalho Noturno, realizada em 1998 em uma indústria no Rio de Janeiro. ${ }^{1}$ Procurou-se enfatizar, em especial, aspectos das relações de gênero, tanto interno como externo do ambiente fabril, buscando o diálogo com questões como divisão sexual do trabalho, qualificação profissional, trabalho doméstico e concepções relativas às definições de trabalhos "pesados" e "leves" e sua possível associação com a saúde dos(as) trabalhadores(as). Esta proposta surgiu da constatação feita pela equipe de pesquisa, em um primeiro relatório, ${ }^{2}$ de que o material empírico obtido e apresentado em sua totalidade suscitava um debate que não só o aprofundava no que concerne às relações de gênero, bem como possibilitava abordar o mundo do trabalho. Gênero e trabalho, portanto, lançam luzes um sobre o outro, e revelam aspectos em que a produção e a reprodução imbricam-se indissociavelmente.

\section{ESTUDO EMPÍRICO}

A pesquisa original refere-se a operários e operárias que trabalham à noite em uma fábrica do setor de plásticos, que produz embalagens para colônias, xampus e si- milares. Nos setores da produção com atividade noturna, a jornada é das 22 às 06 horas de segunda a sexta-feira, com folgas nos fins de semana. $\mathrm{O}$ estudo incluiu todos os trabalhadores do turno da noite (60 pessoas), porém, em razão das demissões e remanejamento de pessoal, nem todas as pessoas participaram de todas as etapas de coleta de dados. ${ }^{3}$

Para este artigo, foram retomados os dados produzidos pelas entrevistas semi-estruturadas, nas quais abordaram-se aspectos gerais do trabalho noturno, vantagens, desvantagens e seus efeitos no cotidiano, principalmente quanto à organização das atividades durante o dia. $\mathrm{O}$ roteiro incluiu ainda temas referentes às concepções sobre o sono, a fadiga e a saúde, bem como suas mudanças com base no trabalho noturno. Também inquiriu-se sobre as atribuições e relações de gênero fora da fábrica, no dia-adia dos entrevistados.

A análise aqui apresentada refere-se a um grupo de dez pessoas ${ }^{4}$ - cinco homens e cinco mulheres - cuja seleção contemplou a diversidade que se encontrou quanto à situação conjugal e à presença de crianças na casa, fatores relevantes para a compreensão do cotidiano. O grupo era composto de dois homens solteiros e três casados (inclu- 
indo união livre), dentre os quais dois tinham filhos de até 10 anos; quanto às mulheres, duas eram solteiras, duas casadas e uma separada e, com exceção das solteiras, todas tinham filhos naquela faixa etária.

As entrevistas abordaram (1) o Sono, com ênfase nas vivências de dormir de dia, hábitos, queixas e alternativas adotadas no dia-a-dia e (2) as Relações de Gênero, em que se reuniu relatos sobre diferenças entre homens e mulheres no trabalho noturno e no trabalho doméstico, suas repercussões na vida afetiva, sexual, social e familiar. Trabalhou-se com as entrevistas como um conjunto, com seleção de falas ilustrativas para compor um "mosaico" de significados, encadeados na forma de um texto que procurou seguir as argumentações em suas lógicas e ambivalências.

Esse estudo baseia-se em dois aspectos importantes observados no material discursivo. O primeiro diz respeito ao "desencontro" de horários dessas pessoas em relação à família, aos amigos e à comunidade em sua totalidade. ${ }^{5}$ Ao contrariar a divisão socialmente adotada em relação às 24 horas do dia (em que a noite é geralmente dedicada ao repouso e o dia, às atividades), o trabalho noturno demanda esforços do/a trabalhador/a para compatibilizar o sono com a realização das atividades diurnas. Portanto, as relações de gênero associadas ao trabalho adquirem novos contornos quando se trata do trabalho realizado à noite, pois ele implica mudança substancial na forma de organizar o dia, que tende a ser mais complexa para as mulheres, pois detêm maior carga de trabalho doméstico. Cabe ressaltar a atualidade desse tema, por causa do aumento da participação feminina na força de trabalho, que inclui um contingente de mulheres que trabalham à noite em indústrias, onde o trabalho noturno era restrito aos homens até a Constituição de 1988.

O segundo aspecto faz menção a um modo de organização social do trabalho que divide e hierarquiza culturalmente as diferenças entre homens e mulheres. Essa lógica fez-se presente de forma contundente nas entrevistas tanto masculinas, como femininas. Desse modo, para melhor se tratar as relações de gênero no trabalho noturno, deve-se antes refletir sobre as atribuições de gênero, que envolvem a relação de homens e mulheres no processo de trabalho - tanto profissional como doméstico. Essas relações envolvem necessariamente a realidade de homens e mulheres não só na fábrica, como no dia-a-dia fora do trabalho. É nessa perspectiva que se adota a divisão sexual do trabalho (Kergoat, 1989) como conceito fundamental, como se discutirá a seguir.

\section{DIVISÃO SEXUAL DO TRABALHO E QUALIFICAÇÃO PROFISSIONAL}

Desde os anos 70, quando emergiu como teoria e problema de pesquisa sociológica no campo das Ciências Sociais, até nossos dias, inúmeras leituras puderam ser feitas sobre a divisão sexual do trabalho, e a que melhor identifica as origens dessa discussão enfatiza o caráter sexuado das relações sociais. Nesse panorama, as diferenças entre homens e mulheres engendram desigualdades quanto ao valor dos trabalhos masculinos e dos femininos (Hirata; Kergoat, 1998). Por essa perspectiva, encontram-se trabalhadores dotados das atribuições de seus gêneros e, por elas, hierarquizados no valor de suas atividades. A assimetria e a hierarquia entre os trabalhos desenvolvidos por homens e por mulheres espelham a forma desigual com que se relacionam na sociedade e, assim, o trabalho é dividido conforme a organização que permeia as relações de gênero.

Por meio da atuação de outras disciplinas, como História e Antropologia, a divisão do trabalho entre os sexos alcançou novos contornos que ampliaram seus debates. Uma importante contribuição refere-se à caracterização da divisão sexual do trabalho como um fenômeno presente em todas as culturas e sociedades; sua organização varia no tempo e no espaço e não consiste em única forma de divisão do trabalho, mas às outras se articula (Kergoat, 1989). Seu principal elemento em comum, em todas as suas variações, está na hierarquização do trabalho conforme o sexo de quem o realiza.

Se, por um lado, a organização entre os sexos não é a única forma de divisão do trabalho em uma cultura ou sociedade, e tampouco é exclusiva das nossas sociedades ocidentais, por outro, sua grande importância reside na capacidade de conferir visibilidade às relações sociais. Isto porque "a divisão sexual do trabalho é o suporte empírico que permite a mediação entre relações sociais (abstratas) e práticas sociais (concretas)" (Hirata; Kergoat, 1998:95, tradução livre).

Sua "universalidade", longe de cristalizar as relações entre os sexos, conferindo-lhe um caráter da ordem da natureza e da imutabilidade, inscreve a divisão sexual do trabalho radicalmente na ordem do social, uma vez que em seu centro estão a hierarquia e o valor. É importante ressaltar que esses elementos são frutos de relações sociais, uma vez que são elas que constroem e compartilham sentidos e significados sobre o mundo, e não o contrário - como poderiam postular abordagens deterministas e essencialistas. 
Este é um importante ponto, bastante beneficiado pelas contribuições do feminismo com sua crítica à biologização dos papéis sociais. Com a desnaturalização do trabalho, ele deixou de espelhar a "ordenação natural" das capacidades masculinas e femininas e passou a ser visto como resultado das relações sociais, ou seja, um "constructo social”, nos termos de Kergoat (1989). Essa ruptura com as concepções deterministas da natureza sobre as relações sociais permitiu que outros pontos pudessem ganhar evidência nos debates sobre a divisão do trabalho entre os sexos.

A mesma hierarquia que organiza, pelo valor, as diferenças entre trabalhos realizados por homens e por mulheres, possibilitou o não reconhecimento dos trabalhos que ocorrem na esfera doméstica e são relacionados ao mundo privado. Os cuidados, geralmente atribuídos às mulheres, com as crianças, a casa e seus moradores, não são considerados trabalhos pois tratar-se-iam "apenas" de atividades de manutenção das condições para a realização do "autêntico trabalho", este sim, verdadeiramente produtivo, posto que se consubstancia em produtos cujos valores são monetarizáveis. Além disso, este trabalho é pago por meio de salário e realizado no âmbito público.

Esta separação entre trabalho produtivo e reprodutivo é um dos principais elementos organizadores da atribuição de hierarquia e valor que legitima o que seria um "verdadeiro trabalho", conferindo poder a quem o realiza e perpetuando as condições para a divisão e desigualdade do trabalho entre os sexos.

Apesar de a entrada das mulheres no mercado de trabalho nos considerados "setores produtivos", o valor de sua atuação continua atrelado ao universo hierarquicamente subalternizado da reprodução no mundo doméstico. Seu trabalho e sua identidade como trabalhadoras continuam a ser de mulheres que, de certa forma, "não deveriam estar ali", pois seu lugar permanece referido ao da casa, ao da maternidade e ao do cuidar dos outros (Brito; Oliveira, 1997).

Desde sua sistemática entrada no proletariado, no final do século XIX e início do XX, a mulher insere-se no "setor produtivo", sendo mantido, entretanto, o modelo atribuído ao feminino, voltado para o mundo privado e da reprodução. Um exemplo muito ilustrativo desse período encontrase na análise da imprensa do movimento operário da cidade de São Paulo (Rago, 1987). Este, mesmo possuindo uma visão de mundo fortemente impregnada pelo anarquismo, que rivaliza com o projeto burguês, no que diz respeito às mulheres também idealiza uma "rainha do lar". A imprensa re- produz os atributos conferidos às mulheres como doces, ingênuas e frágeis (física e moralmente). O discurso operário, de modo geral, possui um tom paternalista, ao ver a mulher como uma "flor frágil" que deveria ser protegida e, sempre que possível, reconduzida ao que seria seu legítimo lugar, o espaço doméstico.

Como defende Kergoat (1987:89), é de grande importância a articulação entre a produção e a reprodução, uma vez que: "por não se considerar o conjunto produção/reprodução como um todo indissociável, tudo se passa como se devêssemos encontrar um princípio de coerência único, e que essa coerência devesse ser relacionada a um lugar institucional: a família ou a fábrica. O que é apenas, no fim das contas, uma das maneiras de pôr em funcionamento a dicotomia clássica: aos homens, o trabalho assalariado - e quando as mulheres inserem-se positivamente nesse espaço, isto continua a ser considerado como excepcional - às mulheres, a família: lugar de enclausuramento e de opressão; lugar fechado".

Desse modo, portanto, não se avançará no mundo sexuado do trabalho se não se articular nas análises as relações de gênero e as de classe. Pois, como a produção e a reprodução, a casa e a fábrica são espaços que não se encontram isolados em si; pelo contrário, interagem por meio de relações sociais fundamentais. O sexo dos trabalhadores é uma importante diferença no mundo do trabalho que, geralmente, encontra-se ocultada pela "uniformidade" de classe. E, no entanto, é ao se colocarem na situação de trabalhadores, ao venderem sua "força de trabalho" como economia clássica, que as relações de gênero adquirem concretude e visibilidade privilegiadas.

Isso significa que se deve adotar em nossos estudos, ao mesmo tempo, esses dois grupos de relações sociais: de gênero e de classe, de forma a escapar de reduções e simplificações que ou bem abordem a opressão em uma ou bem a exploração em outra, compactuando com a hierarquização das relações sociais ou com a abordagem de uma em detrimento da outra (Kergoat, 1984; 1987). Como, aliás, tão bem define Hirata (1995:40): "Relações de classe ou relações de sexo, antagonismos de classe ou antagonismos de sexo, tudo se passa como se a importância dada a uma destas relações implicasse deixar a outra em um plano secundário. Foi Danièle Kergoat quem conceituou estas duas relações sociais em termos de 'coextensividade', isto é, em termos de recobrimento parcial de uma pela outra."

Neste "recobrimento parcial de uma pela outra", destaca-se a questão da qualificação profissional como im- 
portante ponto de articulação entre relações de classe e de gênero em nosso dias, como no exemplo do início do século XX (Rago, 1987).

Mediante a perspectiva de "coextensividade" das relações sociais, pode-se perceber que, como no passado, sobre a trabalhadora é projetada a imagem da dona-de-casa (Brito; Oliveira, 1997). Portanto, sua "qualificação" é associada a "habilidades naturais", como paciência, destreza, detalhismo e movimentos finos. Como estes atributos, porém, estão inscritos no mundo da reprodução e da feminilidade, não possuem prestígio e status de qualificação no mundo do trabalho assalariado, existindo, quando muito, na forma de "qualidades femininas" (Kergoat, 1984).

As qualificações femininas, forjadas ao longo de suas vidas nos saberes, disciplinas e habilidades aprendidas e desenvolvidas nos trabalhos domésticos, mesmo quando largamente empregadas pelas fábricas, não são equiparadas àquelas adquiridas em cursos e treinamentos formais. E mais: além de não serem reconhecidas em prol da trabalhadora, ainda "desqualificam" os postos de trabalho que delas se servem. É como se, onde as qualificações femininas forem postas em uso, mais simples será o trabalho, uma vez que ele pode ser feito com base em conhecimentos tidos como "naturais" ou "espontâneos".

Em suas pesquisas, Rizek e Leite (1998: 291) apontam que as justificativas gerenciais para a contratação de mulheres para postos "sem qualificação" ressaltam as habilidades e capacidades femininas que seriam adequadas ao "trabalho simples", em que: "o trabalho feminino fabril é visto como uso das habilidades e inabilidades corporais femininas: destreza e paciência, atenção e minúcia são naturalizadas constituindo parte da "natureza feminina'".

As qualificações femininas permanecem "invisíveis", portanto, em razão dessa subalternização conferida ao valor do trabalho feminino, sendo este capturado em uma esfera de informalidade e espontaneidade. São considerados como "talentos de mulher", embora sejam reconhecidos pelos gerentes como vantagens para o processo produtivo, não se traduzem como carreira ou salário (Soares, 1998). Desqualificação do trabalho feminino e depreciação de seus postos de trabalho compõem um quadro de verdadeira "segregação ocupacional" para as trabalhadoras, à medida que acarretam grande concentração de mãode-obra feminina em postos de trabalho mal remunerados, com organização rígida, repetitiva e em condições de execução precárias (Soares, 1997).

Como desdobramento das condições adversas da segregação ocupacional, ocorrem a reafirmação e recriação da subalternização do trabalho feminino, uma vez que sua rígida organização temporal, na maioria das vezes, não possibilita a complementação dos estudos ou a liberação de seus postos de trabalho para participar de cursos e (re)qualificações profissionais. Um círculo vicioso reproduz a segregação: postos de trabalho tidos como desqualificados possuem rígida organização temporal que dificulta o acesso a qualificações formais para o mundo do trabalho, ao mesmo tempo que, por tais postos serem considerados de baixa ou nenhuma qualificação, não haveria porque empreender gastos com as trabalhadoras.

Marcas dessa situação podem ser encontradas em pesquisas realizadas sobre o acesso das trabalhadoras a treinamentos, nas quais se aponta como este é restrito, se comparado com os trabalhadores do sexo masculino (Rizek; Leite, 1998). Para além de decisões de caráter "puramente técnicos", a qualificação do trabalho lida com a base valorativa oriunda das relações sociais, de forma que se garanta a produção (Rolle, 1989).

A lógica da qualificação atende ao fluxo do trabalho reproduzindo as atribuições de gênero. $\mathrm{O}$ pouco acesso ao treinamento técnico e a dificuldade em galgar melhores colocações profissionais promovem o confinamento feminino nesses postos precários de trabalho. Por sua vez, as trabalhadoras interiorizam a banalização de suas próprias qualificações e se vêem com poucas perspectivas de melhoria de suas condições (Kergoat, 1984).

Em busca de novos contornos e detalhes, avançar-se-á nessas questões com base nos discursos dos trabalhadores e trabalhadoras. Suas argumentações além de ilustrar, dialogam de modo bastante preciso com o universo conceitual da divisão sexual do trabalho articulando, dentro e fora da fábrica e do turno noturno, o cotidiano de cada um, principalmente no que concerne à divisão dos trabalhos domésticos e responsabilidades familiares.

\section{"VOCÊ TEM QUE CHEGAR EM CASA, FAZER SUA OBRIGAÇÃO"}

Tanto homens quanto mulheres freqüentemente relacionaram nas entrevistas os cuidados com a limpeza e a arrumação da casa, o preparo das refeições e a atenção às crianças como atribuições femininas. No trabalho noturno tal aspecto adquire relevância especial, uma vez que tais atividades comprometem seriamente o tempo para dormir. Diz Elvira: " "A gente chega em casa (...) tem que dividir o descanso com as tarefas domésticas entendeu, e fica meio complicado, porque você fica assim meio dese- 
quilibrada ou você descansa ou você cuida das tarefas, ou você cuida dos filhos entendeu? Aí é difícil...”.

Por um lado, o acúmulo de trabalhos sobre as mulheres pode ser entendido não só como a "naturalização" da atribuição dos trabalhos domésticos femininos mas, também, como um fenômeno articulado a uma prerrogativa masculina que facilita a ausência dos homens nessas mesmas atividades (Hirata, 1995). Aos homens já estariam imputados o trabalho considerado produtivo e a dispensa dos trabalhos domésticos, ao passo que para as mulheres o trabalho doméstico permanece como determinação, sobretudo em uma época em que cada vez mais trabalhadoras entram e procuram manter-se no mercado de trabalho (Hirata; Kergoat, 1998). Assim, pôde-se ouvir das mulheres falas bastante claras, como a de Marina, sobre esse caráter de "obrigatoriedade" dos trabalhos domésticos: "Você tem que chegar em casa, fazer sua obrigação".

Por outro lado, a prerrogativa masculina de não adesão a esses trabalhos domésticos estende a eles uma vantagem significativa para se adaptarem mais facilmente ao trabalho noturno. Clarice declara: "Por que ele é homem né... quer dizer, ele agüenta mais e ele não tem o que fazer dentro de casa, quem faz sou eu mesma, quer dizer, de noite ele agüenta, é só chegar em casa e dormir".

Os homens confirmam a prioridade para dormir em sua rotina diária. Eles dormem bastante porque precisam preparar-se para o turno noturno e, também, porque podem entregar-se mais livremente à satisfação dessa necessidade: Antenor declara: "É, eu só descanso. Durante o dia eu descanso, você pode até ver, eu durmo... eu chego em casa umas 8 e meia, aí escuto um pouco o rádio e tal, olho as crianças e tal, aí vou deitar, não adianta me chamar que eu não faço nada, não faço nada, nada, nada, nada... só descanso. Porque se eu não descansar, quando eu chegar aqui no serviço, não agüento fazer, entendeu?".

Conhecer as lógicas referidas ao cotidiano aproxima, com mais informações das concepções sobre as vidas de nossos entrevistados e, principalmente, das relações sociais que mediam seu dia-a-dia. Estudos sobre a permanência masculina no espaço domiciliar, seja por motivo de desemprego, seja porque exerçam atividade autônoma, estejam estudando ou se encontrem incapacitados para o trabalho; apontam que sua participação nos trabalhos domésticos é sempre inferior ao das mulheres (Bruschini; Ridenti, 1995; Marshall, 1998).?

Em especial, quando homens desenvolvem em suas casas atividades como autônomos, seus trabalhos, embora sejam realizados no âmbito doméstico, continuam a ser considerados por eles próprios como qualificados. Trabalhar em casa representa para os homens não estar submetido a esquemas de produção rígidos e controlados, podendo se organizar com flexibilidade quanto a seus próprios horários e atividades. Interessante destacar que, independente do espaço onde o trabalho é realizado, a noção de qualificação - e o decorrente prestígio das tarefas executadas - acompanha o sexo do trabalhador. Outro ponto importante consiste na capacidade do trabalhador masculino, no âmbito doméstico, de realizar uma clara distinção (espacial e temporal) entre o seu trabalho autônomo e o do domicílio, conseguindo preservar sua vida profissional, mesmo quando a exerce em casa. Portanto, os homens que trabalham em casa parecem não deixar que as demandas do lar interfiram em sua atividade profissional. Embora sua maior permanência em casa favoreça sua aproximação com os filhos e a moradia, sua participação nos trabalhos domésticos caracteriza-se por uma relação mais distanciada e menos envolvida, em comparação com mulheres que também desenvolvem atividades profissionais autônomas em casa (Bruschini; Ridenti, 1995).

Também em nossa pesquisa atemática quanto aos cuidados com os filhos possibilitou aprofundar alguns interessantes aspectos das relações entre homens e mulheres que vivenciam o trabalho noturno. Como os demais trabalhos domésticos, a atenção às crianças parece constar do conjunto das atribuições femininas, a tal ponto, que o próprio ingresso e/ou a permanência no turno noturno foram justificadas pela possibilidade da mulher de cuidar dos filhos durante o dia. Elvira justifica: "porque eu tenho 2 filhos e a minha mãe tem esse problema né, hipertensa... Então tudo tem que ser por minha conta, então o melhor horário seria à noite mesmo, porque eu tenho o dia todo livre para fazer isso, ensinar dever da escola, fazer as tarefas domésticas e à noite quando eu saio, já está praticamente na hora deles dormirem."

Entre os homens entrevistados, também a disponibilidade durante o dia para cuidar dos filhos foi apontada como um dos importantes motivos para explicar a entrada e/ou permanência no trabalho noturno. Entretanto, como este cuidado é comumente encarado como tarefa feminina, muitos mencionam esta "vantagem" do trabalho noturno para as mulheres com filhos, não lhes ocorrendo incluir a si próprios, ou aos outros homens, também como beneficiados. Pedro tem a seguinte opinião: "Só serve se for à noite (...) Porque ela tem o sábado livre, ela pode lavar as roupinhas dela... entendeu? E também porque ela não tem com quem deixar os filhos, então o marido chega fica com 
o filho à noite e ela pode estar trabalhando, ganhando um dinheirinho para ajudar o marido... ela sai de casa, quase o marido não fica com o filho, porque a hora que o marido vai dormir, é a hora também que a criança vai dormir".

Vale ressaltar que um entrevistado mencionou que, há certo tempo, havia assumido alguns cuidados com os filhos, fato que promoveu uma radical reestruturação em seus horários de sono, agora sincronizados pelos cuidados com as crianças. Relata Américo: "Há pouco tempo agora eu vou... pego, levo as crianças para a escola, chego lá... a mãe deles trabalha de manhã, aí eu chego lá faço café, arrumo eles, aí levo eles para escola... um estuda perto, o outro lá em Pilares. Aí eu levo eles, chego em casa 8 horas, tomo um banho, lá para 8 e meia... eu estou dormindo, aí eu acordo 11 horas, vou buscar eles... aí quando é 1 hora mais ou menos, uma e meia aí eu volto a dormir de novo. Aí acordo, às vezes 6 horas, 8 e meia aí tomo um banho e vou se arrumar para vir trabalhar".

O motivo de alteração na rotina deste entrevistado está em consonância com as atribuições de tarefas diferenciadas entre homens e mulheres, que aqui se tem apresentado. Ou seja, os cuidados com as crianças geralmente são responsabilidade feminina, mas podem passar a ser atribuição masculina em circunstâncias extremas, como diante da ausência ou impossibilidade de outra pessoa arcar com tal tarefa. "Porque eles ia com a prima deles, aí eles começou a não querer ir para a escola com ela, aí eu tive que passar a levar... se não eles não iam para a escola", afirmou, Américo.

\section{"UM EMPREGO PRÁ PODER RESPIRAR"}

Por um lado, a adaptação ao trabalho noturno muitas vezes é apresentada em um conjunto de argumentos, ou seja, articulada a outras questões que facilitam ou prejudicam o desempenho no turno noturno, variando desde aspectos fisiológicos, físicos e mentais até questões que envolvem a necessidade imperiosa de estar empregado. Essas explicações, porém, adquirem nova relevância quando consideradas com base em uma leitura das relações de gênero. Por exemplo, dispor ou não da ajuda de um familiar para cuidar da casa ou dos filhos, aliviando alguns encargos de mulheres que também trabalham à noite, foi mencionado como fator decisivo para a adaptação ao trabalho noturno.

Mas, por outro lado, a adaptação pode ser entendida como conseqüência da necessidade do emprego e da vontade de trabalhar, que superariam até as dificuldades im- postas pelo turno noturno, Antenor diz: "Só vontade de trabalhar... a pessoa que tem vontade de trabalhar, cara, supera tudo, não é? Ainda mais se estiver necessitada, se estiver precisando, aí... não tem nada que segure. Eu, vim para cá, como eu disse né, estava precisando, e fiquei até hoje".

A necessidade e a importância do trabalho bem como o medo de perder o emprego adquirem destaque e contornos dramáticos nas entrevistas, principalmente nas falas dos homens, como Pedro: "eu me preocupo muito em... por exemplo, perder esse emprego, com essa crise de desemprego aí, se... juntando a idade, juntando a crise de desemprego, essas exigências com idade, esses negócios, o quê que pode me restar?"

Cabe reconhecer, evidentemente, que a perda do emprego e o temor de não se recolocar no mercado de trabalho ameaçam tanto homens como mulheres, sobretudo em nossos dias. Contudo, deve-se destacar que, em especial para os homens, o trabalho assalariado quando ameaçado é motivo de sofrimento e angústia, sendo também visto, pelos próprios trabalhadores, como uma responsabilidade masculina para com a família e a casa, como bem ilustra Sarti (1996:72): “A categoria pai de família complementa a auto-imagem masculina. A moral do homem, que tem força e disposição para trabalhar, articula-se à moral do provedor, que traz dinheiro para dentro de casa, imbricando-se para definir a autoridade masculina e entrelaçando o sentido do trabalho à família."

Prover as necessidades da família, antes de tudo, parece consistir em uma atribuição que gera novos sofrimentos à vivência masculina no mundo do trabalho. Antenor declara:"minha filha tinha 3 anos, era pequena, aí poxa, para mim ficar desempregado com filha pequena né, aí eu pedi a um colega, falei: "pô, arruma serviço pra mim..." ele falou: "serviço lá não é bom, e tal..." me preparou né, aí eu falei: "tudo bem cara, eu quero só um serviço para... um emprego para mim poder respirar...".

Este próprio entrevistado, com base na história de sua união com a atual companheira, tão bem ilustra a relação que haveria para um homem entre trabalho e assunção de responsabilidades afetivas e familiares: "Eu já conhecia ela, mas eu não era casado. Eu tinha um filho com ela, mas não era casado não. Depois que eu trabalhei... passei a trabalhar aqui é que eu fui morar com ela. Na época também eu não tinha condições de botar também casa para ela não, eu ganhava pouco... dava 2 salários ou até menos, ganhava mal... mas era o que eu ganhava né."

A responsabilidade de prover o sustento familiar, tradicionalmente atribuída aos homens, gera importantes 
impactos na criação e estruturação das próprias famílias. Deve-se considerar que, se o trabalho ocupa um lugar tão central na identidade masculina, e socialmente lhe é atribuído como mais importante do que para as mulheres, o efeito da perda do emprego, portanto, deve ser mais severo para os homens, por ser motivo de vergonha e humilhação (Kjellberg, 1998) - sobretudo em períodos de redução de postos de trabalho, de vagas com vínculo empregatício e de intensas modificações das técnicas produtivas, em que as possibilidades de realocação no mercado ficam menores. Convém destacar que tais situações de "crise do trabalho" em geral ocorrem em períodos de crise na acumulação de capital (Freyssenet, 1989).

Situações adversas no mundo do trabalho radicalizam os efeitos da responsabilidade imputada aos homens. Em situações limites, ele não formará família, ou a abandonará caso se perceba impotente para responder financeiramente por ela. No universo das relações de gênero, no qual a identidade masculina ainda se referencia mais ao mundo público do que ao privado, seu "passaporte" para o âmbito doméstico e à vida familiar precisa estar em dia na forma de dinheiro que responderá às necessidades da casa e de seus habitantes.

Esta responsabilidade de gênero aponta para a idéia de que uma união estável - formal ou não - com coabitação teria que, necessariamente, estar fundamentada numa relação assimétrica entre homens e mulheres, uma vez que caberia àqueles a atribuição de prover. Dessa maneira, quando as atribuições de gênero estiverem mais rigidamente unidas aos atributos tradicionais, as uniões serão originadas em grande parte quando o homem puder "constituir família", ou seja, dispor de rendimentos próprios e superiores (quando não absolutos) aos de sua parceira. Adotando esse ponto de vista, pode-se, então, entender essa "assimetria estruturante" como um dos elementos, por exemplo, na recorrente diferença entre a idade dos homens e das mulheres quando se casam. Estudos baseados em dados referentes a casamentos legalizados (Berquó, 1998) apontam que, nos últimos vinte anos no Brasil, os homens casam-se com idades maiores às de suas esposas, com cerca de 3,6 anos de diferença. A diferença entre as idades pode representar o tempo necessário aos homens para galgarem melhores colocações no mercado de trabalho, ao menos, para estarem em condições de manterem uma casa e/ou ganharem mais do que suas esposas.

Como dissemos, porém, esta lógica atende com maior coerência quanto mais rígidas forem as relações de gênero conforme as atribuições tradicionais para as masculi- nidades e feminilidades. A sociedade brasileira vive atualmente mudanças importantes, como o aumento da participação feminina na força de trabalho (Irrrag, 1995; Fundação Seade, 1997) e o crescente número de famílias chefiadas por mulheres (Oliveira, 1996). Para essas famílias, em especial, o trabalho noturno parece constituir-se em uma alternativa para mulheres que, por diversos motivos, precisam prover a subsistência da família, assumindo para si essa atribuição apontada nas entrevistas como prioritariamente masculina. Nelson, um dos entrevistados, diz: "a maioria das que trabalham aqui tem filhos (...) uma grande realidade dessa firma é que a maioria das admissões das mulheres, são mulheres que tem filho, que o marido deixou e precisou cuidar dos filhos, né?"

Para as mulheres no trabalho noturno que assumiram a atribuição de provedora da família, existe grande sobrecarga que agrega as tarefas domésticas, a atenção aos filhos, o trabalho noturno e a responsabilidade de garantir $o$ atendimento às necessidades familiares e da casa.

De modo geral, no mundo do trabalho, a falta de reconhecimento do trabalho das mulheres e de suas qualificações, que se expressa em salários menores e carreira depreciada, aliada à sobrecarga dos trabalhos domésticos, está agravando a "feminização da pobreza" (Brito; Oliveira, 1997). Essa situação, além de ocasionar grandes agravos pessoais, em especial à saúde, das mulheres chefes de família, atinge também aos que estão sob seus cuidados diretos como crianças e idosos, ampliando a gravidade de seus impactos sociais.

\section{"É SERVIÇO PRA MULHER MESMO"}

Outra atribuição de gênero apontada pelas entrevistas como "essencial" ao sexo dos trabalhadores faz menção à força física e à resistência que, em geral, os homens teriam a mais que as mulheres. Pode-se perceber, também, que tais atribuições e expectativas são apresentadas nas entrevistas na forma de pares de oposição, contrapondo homem/mulher, "sexo-forte"/"sexo-fraco". Nesse sentido, parece bastante ilustrativo o depoimento de Sabrina, uma entrevistada, que articulou essas caraterísticas, organizadas em pares de oposição, no que tange à adaptação ao trabalho noturno: "Ah sei lá, mulher é mais sensível ou agüenta menos, homem não, é mais farrista, sei lá, se tiver que pegar uma noitada pela frente, eles pegam, não estão nem aí. Eu acho que trabalhando ou na farra, segue tranqüilo. A mulher não, eu pelo menos tiro por mim, mais fraca, eu acho a mulher mais sensível para trabalhar à noite, 
para levar uma noite toda assim pela frente. Homem não, eu olho o homem assim com o olho de que ele pode mais."

A identificação de força e resistência, como características predominantemente masculinas, estende-se às classificações dos processos produtivos da fábrica criando, por sua vez, o "serviço de mulher" e o "serviço de homem" como duas categorias recorrentes. João pensa desse modo: "Esse serviço que as mulheres trabalham de operadora aí é moleza. É serviço pra mulher mesmo. Porque é um servicinho leve, você pega frasco e vai arrumando... Pra homem, não! Homem você... a gente sendo homem, a gente pega qualquer serviço... Aquilo é que é serviço de mulher, mesmo. O que eu faço é forçado. Eu faço é abastecer máquina. Tem que pegar o material e botar pra cima. Carrega no carrinho mas, quando chega lá, tem que carregar tudo no ombro e põe na máquina. Mais forçado que tem é esse."

O mundo do trabalho também informa sobre as características atribuídas às mulheres. Se, por um lado, os homens são identificados pela força e resistência, por outro lado, as mulheres são dotadas de disciplina e organização Clarice lembra: "Antigamente aqui não admitia mulher de noite não, era só homem... mas eu acho que homem fazia bagunça, dormia, não dava conta da produção, aí colocaram mulher. ... Aí botaram mulher, porque mulher é mais organizada né... tem medo também, porque homem... por exemplo, o chefe, homem não respeita o chefe, e a mulher já fica com medo né, já tem aquele receio de falar alguma coisa, de reclamar... homem não, homem se tiver que falar vai falar mesmo na cara... mulher não."

Assim, as mulheres são descritas como mais cordatas e pacíficas em suas relações com a chefia e os colegas, características quase sempre apontas como mais vantajosas, sobretudo porque os homens, na lógica das oposições, são caracterizados como mais rebeldes e truculentos. É assim que Antenor define: "Mulher não, mulher sabe que tem que fazer aquilo, não fez a gente chama atenção e ela fica quieta. O homem não, o homem já quer discutir, já acha que é mais forte entendeu?"

Essas atribuições de gênero são trazidas para o mundo do trabalho tanto pelas chefias e gerências como pelos próprios trabalhadores, uma vez que ambas as classes, embora vivam grandes diferenças sociais, estão no mesmo mundo da cultura e compartilham de seus significados mais enraizados.

Uma importante pesquisa, realizada com chefes de setor de recrutamento e seleção sobre os critérios adotados para a contratação, aponta que os atributos de masculini- dade e feminilidade - na forma de concepções sobre os sexos - são claros norteadores para os preenchimento de vagas: "Segundo essas concepções, existem trabalhos de homem e trabalhos de mulher, que requerem aptidões diferenciadas e que justificam a divisão sexual do trabalho dentro da fábrica" (Silva, 1995). Do mesmo modo, mulheres deveriam corresponder às expectativas de um feminino habilidoso, delicado, paciente e, principalmente, dócil na fábrica como em casa (Rizek; Leite, 1998).

A "calma", tão valorizada entre os atributos imputados às mulheres, é apreciada pelas chefias como qualidade imprescindível para trabalhos que exigem paciência, delicadeza e minúcia. São trabalhos tidos como "leves", mas nos quais as trabalhadoras também precisam de calma para enfrentar longos períodos de tarefas repetitivas, em postos de trabalho que geralmente são altamente mecanizados. Do mesmo modo, deve-se contratar trabalhadoras dotadas desta "virtude" para que estabeleçam relações dóceis, cordiais e de obediência com seus colegas e chefes de setores. Enfim, as trabalhadoras em seus trabalhos "leves" só precisariam ter "a virtude da calma", para trabalhar e obedecer.

Quanto aos homens, ao lado de sua qualificação reconhecida ou presumida, um importante atributo da masculinidade para o mundo do trabalho é o da virilidade, acionada para atividades tidas como mais pesadas, por envolverem perigo ou manuseio de peso ou uso de força. De modo geral: "O estudo das atividades de trabalho segundo o sexo e o par masculinidade/virilidade e feminilidade desvenda o poder dos estereótipos sexuados no trabalho (a virilidade é associada ao trabalho pesado, penoso, sujo, insalubre, algumas vezes perigoso, trabalho que requer coragem e determinação, enquanto que a feminilidade é associada ao trabalho leve, fácil, limpo, que exige paciência e minúcia)" (Hirata, 1995:42).

Um trabalho que, por sua vez, demanda e desafia a virilidade de um trabalhador, está acionando sua identidade masculina, podendo, com isso, favorecer condutas prontas e vigorosas, bem como situações em que a saúde e a integridade (física e mental) sejam postas em risco. Talvez, muitos dos ditos "atos inseguros", que geraram acidentes de trabalho ou doenças ocupacionais, possam ter suas raízes na mobilização de atribuições de gênero. ${ }^{8}$

Em seu trabalho com classes populares, Leal (1998: 392) aponta como, também, o trabalho e a sexualidade entrelaçam-se nos significados masculinos, em que o atributo da virilidade é fundamental: "Trabalho", "serviço" e "esforço" são impressões-chave que aparecem associadas 
à prática sexual masculina e numa perspectiva exclusivamente masculina. Expressões que, por um lado, potencializam a noção força-esforço, virilidade, e, por outro, redimensionam uma esfera - o trabalho - que é socialmente concebida como do masculino.

Um importante ponto na divisão idealizada entre "serviço de homem" e "serviço de mulher" baseia-se no emprego da força física, o que promove outra forma de distinção e atribuição de valores às atividades como: "pesadas-difíceis" ou "leves-fáceis". Assim, carregar peso parece ser um dos poucos esforços visíveis e reconhecíveis no trabalho, quanto aos demais, em geral realizados pelas trabalhadoras, permanecem invisíveis.

O peso do trabalho "leve" adquire visibilidade se se articular a perspectiva de gênero com a abordagem ergonômica dos postos de trabalho, ${ }^{9}$ de modo que se contextualize esses valores de leveza e peso. Dessa forma, podemos levar em consideração não só o peso em si que o trabalhador precisa deslocar, mas as demais condições que compõem determinada atividade. Por exemplo, nos postos mais mecanizados, considerados "leves" em razão da presença da máquina e onde geralmente se alocam mulheres, ocorrem esforços físicos que podem passar despercebidos, tais como a adoção de posturas desfavoráveis para músculos e ossos, sua manutenção por longos períodos, a repetição sucessiva dos mesmos movimentos e, somando-se a estas, a pouca ou nenhuma possibilidade de sair do posto de trabalho e se locomover a fim de alternar movimentos ou, simplesmente, "dar uma esticada" para romper com o sedentarismo.

Como o manuseio de peso é um importante diferencial que distingue os "trabalhos de homens" dos "trabalhos de mulheres", reafirmando a lógica binária "pesado" versus "leve", as diferenças imputadas aos gêneros, parecem tender a valorizar o esforço físico masculino e subestimar o feminino. Entretanto, deve-se considerar que, quando os homens deslocam pesos, o esforço físico e o trabalho muscular são mais intensos, porém esporádicos; ao passo que nos trabalhos "femininos", esses são moderados, mas contínuos (Brabant, 1990; Vézina; Courville, 1992, Soares, 1998). Reside aí importante diferença que, nem sempre percebida, acarreta graves consequiências para a saúde das mulheres trabalhadoras. ${ }^{10}$

De fato, a título de ilustração, as observações ergonômicas realizadas na fábrica ${ }^{11}$ informaram que grande parte dos homens realmente carrega peso no transporte e abastecimento de insumos para a produção, seu trabalho possibilita maior movimentação pela fábrica e um con- trole mais livre de seu tempo entre os abastecimentos. Tais características, no conjunto das atividades desempenhadas no turno noturno constituem importantes vantagens, sobretudo se comparadas ao trabalho nas máquinas.

Um outro importante diferencial na lógica binária no mundo do trabalho está no atributo de "serviço perigoso" identificado, por exemplo, naqueles geralmente realizados em alturas que oferecem riscos de quedas ou com possibilidade de exposição a materiais tóxicos. Esses são considerados tanto por trabalhadores como pelas chefias, como trabalho pesado e, portanto, "típico" de homem (Kjellberg, 1998; Messing; Elabidi, 1998). Aceitar este risco subestimando os perigos, faz parte das atribuições de gênero que são acionadas no mundo do trabalho, uma vez que um "homem de verdade" não teme o perigo (Messing; Chatigny; Courville, 1996).

Essa divisão entre trabalhos "leves" ou "pesados", de mulher ou de homem, promove desafios à promoção da saúde dos trabalhadores, já que "estereótipos sexuados" contribuem para agravos estereotipados à saúde (Messing; Chatigny; Courville, 1996). De fato, nos trabalhos assalariados femininos, tidos como "leves", há maior dificuldade na identificação dos riscos, principalmente porque as trabalhadoras tenderiam a desenvolver doenças ocupacionais, enquanto os homens estariam mais sujeitos a sofrer acidentes de trabalho (FTQ, 1995; Kjellberg, 1998).

Por fim, deve-se considerar que apesar de gerentes e chefes também serem homens e mulheres, sua situação de classe os colocam numa perspectiva de otimização e de aproveitamento das atribuições de gênero dos trabalhadores, em benefício dos processos produtivos. Portanto, a organização do trabalho aciona atributos de gênero para seu melhor desempenho. Como aponta Hirata (1995), um grande campo de investigação abre-se diante da questão de como a virilidade, a docilidade, as masculinidades e femilidades são expressas, interpretadas, transpostas, negadas ou exploradas no trabalho.

\section{GÊNERO, TRABALHO E SAÚDE: DESCONSTRUÇÕES NECESSÁRIAS}

Uma vez que o trabalho feminino "leve" também tem o seu peso, deve-se, do mesmo modo, destacar que este fica ainda mais pesado, já que a atividade assalariada é exercida "acoplada" aos trabalhos domésticos (RochaCoutinho, 1994). Mesmo nos países onde existe maior participação masculina nos cuidados da casa e das crianças, ainda são as mulheres que dedicam mais tempo a essas 
atividades, ou seja, apesar de conquistar espaço no mundo do trabalho assalariado, os trabalhos domésticos continuam sendo em sua maior parte realizados por mulheres (FTQ, 1995; Marshall, 1998).

A interação entre os trabalhos doméstico e remunerado é um aspecto-chave na compreensão do impacto diferenciado das condições de trabalho sobre a saúde de homens e mulheres, como comenta Vogel (1999). Ao analisar historicamente a inserção das mulheres no trabalho assalariado, este autor ressalta quão pouco se conhece sobre os impactos da divisão desigual do trabalho, enfatizando a "invisibilidade" do trabalho doméstico em seus efeitos à saúde.

Se tantas mudanças puderam ser feitas nas sociedades, se tantos atributos de gênero foram desconstruídos, principalmente ao longo do século XX, no qual as mulheres conquistaram importantes direitos sociais, como ao voto e ao trabalho, é importante considerar que não só o trabalho doméstico feminino precisa adquirir seu efetivostatus nas relações produtivas, como também empregar a força de trabalho masculina nesse trabalho na esfera do privado.

Desconstruir, então, adquire o sentido da redimensão das atribuições aos gêneros, em relação à história inscrita no cotidiano. Por isso, em vez de "proteger" o trabalho feminino com legislações especiais, que podem voltar-se contra as próprias trabalhadoras, pode-se empreender esforços, como alternativa, para "despublicizar" a parte do trabalho masculino que cada vez mais começa a faltar no espaço privado, em especial com a saída das mulheres para o trabalho na esfera pública.

No entanto, caso se volte para uma perspectiva que visa a desconstrução de forma conseqüente da oposição binária masculino-feminino, ao rever as expectativas sobre as mulheres como essencialmente reprodutoras, também deve-se rever as atribuições aos homens como provedores. De forma bem clara alguns trabalhadores mencionaram, sob o aspecto obrigação perante a família, estarem empregados para garantir o mais plenamente possível a satisfação de seus dependentes.

Essas obrigações foram descritas com palavras de angústia e sofrimento, pois perder o emprego ou não mais poder prover as necessidades familiares de forma satisfatória, implica para um homem perder seu "ingresso" no âmbito domiciliar.

No livro A Revolução das Mulheres (Toscano; Goldenberg, 1992:68), Marta Suplicy relata significativamente: "Quantas vezes eu não ouvi mulheres dizendo: 'Eu acho que o que eu ganho é meu. O que é dele é nosso, mas o que eu ganho é dinheiro meu'."
Assim, com a revisão das polaridades masculino-feminino e público-privado, não só as mulheres, mas também os homens podem ser beneficiados. No que tange ao trabalho noturno, estas questões adquirem especial relevância em virtude da inevitável inversão de horários que por si só já acarreta agravos à saúde (Rutenfranz; Knauth; Fischer, 1989). Quando a realização da jornada diurna compete com a premência de sono, é de se esperar que toda a vida sofra perda de qualidade, acirrando os impactos das diferenças homem-mulher.

\section{NOTAS}

Os autores agradecem a Angelo Soares, pela gentileza de disponibilizar farta bibliografia.

1. Pesquisa coordenada por Lúcia Rotenberg, com apoio da Faperj, CNPq e Fundação Ford.

2. Relatório de pesquisa, para a Fundação Ford, referente a auxílio concedido mediante Programa Interinstitucional de Metodologia de Pesquisa em Gênero, Sexualidade e Saúde Reprodutiva.

3. A pesquisa foi desenvolvida em etapas: (1) caracterização do grupo quanto às variáveis sociodemográficas e relativas aos trabalhos profissional e doméstico, (2) quantificação dos horários de sono, (3) análise qualitativa de entrevistas em relação às vivências de inversão de horários, às práticas para lidar com essa inversão e aos fatores considerados relevantes para a adaptação ao horário de trabalho e (4) descrição dos ambientes físico e organizacional da fábrica aliada à caracterização dos postos de trabalho ocupados por homens e mulheres.

4. No total, foram entrevistadas 46 pessoas -29 trabalhadoras e 17 trabalhadores.

5. Resultados anteriores desta pesquisa indicam que a inversão de horários permeia vários aspectos da vida dos(as) trabalhadores(as), que afeta a saúde, o bem-estar, o lazer, os estudos e as relações amorosas (Rotenberg et al., 2001).

6. Os nomes são fictícios.

7. Os dados relativos ao trabalho doméstico mostram que para as mulheres predominam as tarefas domésticas básicas (limpar a casa, cozinhar, lavar e passar roupa), enquanto os homens dedicam-se, geralmente, a atividades eventuais fora do ambiente doméstico, como fazer compras ou ir ao banco (Rotenberg et al., 2002).

8. Entre os estudos sobre a virilidade no mundo do trabalho, existem importantes contribuições feitas por Christophe Dejours $(1997,1999)$ em que a virilidade teria uma conotação sexual e consistiria em um atributo masculino mas que seria compartilhado por homens e mulheres, e acionada por ambos em situações no trabalho onde se deve lutar contra o medo. Nesse sentido, a virilidade para o autor afasta-se da perspectiva de gênero adotada neste artigo, bem como nos demais autores citados, para aproximar-se das discussões sobre estratégias defensivas, no contexto da psicodinâmica do trabalho.

9. Na indústria estudada, os postos de trabalho relativos à produção são ocupados por mulheres, de modo geral. Na ausência delas (em casos de faltas ou nos horários das refeições), ou quando há aumento da demanda de produtos, supervisores e outros trabalhadores ocupam esses postos de trabalho. Grosso modo, homens e mulheres ocupam postos de trabalho distintos em que pode-se dizer que a produção realizada por mulheres e as tarefas relativas à supervisão e ao transporte de matéria-prima ou produto são realizadas por homens. $O$ objeto de trabalho utilizado pelas mulheres é leve (tampas ou frascos de plástico) e manuseado com o auxílio dos 
dedos. Já os homens utilizam a força muscular das mãos, braços e tronco para executarem suas tarefas, que são, basicamente, o carregamento de sacos cheios de material plástico, os quais pesam cerca de $25 \mathrm{~kg}$, além dos que ocupam cargos de supervisão e mecânica.

10. Irá se abordar direta e exclusivamente em discussões apenas os mencionados "esforços físicos e trabalhos musculares", entretanto, deve-se ressaltar a importância dos "esforços mentais" nos postos de trabalhos que por causa dos limites no desenho deste artigo não poderão ser aqui contemplados.

11. Ver nota 9.

\section{REFERÊNCIAS BIBLIOGRÁFICAS}

BERQUÓ, E.S. Arranjos familiares no Brasil: uma visão demográfica. In: SCHWARCZ, L.M. (Org.). História da vida privada no Brasil. São Paulo: Cia das Letras, 1998. p.412-437 [Contrastes da intimidade contemporânea, livro 4].

BRABANT, C. Les normes d'exposition à la chaleur et le travail des femmes: équitables ou discutables? In: BRABANT, C.; MESSING, K. (Org.). Sexe faible ou travail ardu? Montreal: ACFAS, 1990. p.103-114.

BRITO, J.; OLIVEIRA, S. Divisão sexual do trabalho e desigualdade nos espaços de trabalho. In: SILVA FILHO, J.F.; JARDIM, S. (Org.). A danação do trabalho - organização do trabalho e sofrimento psíquico. Rio de Janeiro: Te Cora, 1997. p.245-263.

BRUSCHINI, M.C.A; RIDENTI, S.G.U. Trabalho domiciliar masculino. Estudos Feministas, Rio de Janeiro, IFCS/UFRJ, v.3, n.2, p.363-392, jul./dez. 1995.

DEJOURS, C. Virilité et stratégies collectives de défense dans les nouvelles formes d'organization du travail. Les cahiers du mage. Paris: Iresco/CNRS, v.3/4, p.147-158, 1997.

. A banalização da injustiça social. Rio de Janeiro: Fundação Getúlio Vargas, 1999.

FREYSSENET, M. A divisão capitalista do trabalho. Tempo Social, Revista de Sociologia da USP, São Paulo, USP, v.1, n.2, p.74-82, jul./dez. 1989.

FTQ. Fédération des travaillers et travailleuses du Québec. Quand le travail "léger" pèse lourd. Québec: FTQ, 1995.

FUNDAÇÃO SEADE. Mulher \& Trabalho, folheto 3, mar. 1997.

HIRATA, H. Divisão - relações sociais de sexo e do trabalho: contribuição à discussão sobre o conceito de trabalho. Em Aberto, Brasília, MEC/Inpe, v.1, n.65, p.39-49, jan./mar. 1995.

HIRATA, H.; KERGOAT, D. La division sexuelle du travail revisitée. In: MARVANI, M. (Org.). Les nouvelles frontiers de l'inegalité. Paris: La decouverte, 1998. p.93-104.

IRRRAG - International Reproductive Rights Research Action Group. World Conference on Women. Beijin, 1995.

KERGOAT, D. Da divisão do trabalho entre os sexos. Tempo Social, Revista de Sociologia da USP, São Paulo, USP, v.1, n.2, p.88-96, jul./dez. 1989.

. Em defesa de uma sociologia das relações sociais. Da análise crítica das categorias dominantes à elaboração de uma nova conceituação. In: KARTCHEVSKY, A. et al. (Org.). O sexo do trabalho. Rio de Janeiro: Paz e Terra, 1987. p.79-93.

Q Qualification et division sexuelle du travail. In: Reunião Anual da Anpocs. São Paulo, out. 1984.

KJELLBERG, A. Men, work and health. In: KILBON, A.; MESSING, K.; THORBJÖRNSSON, C.B. (Org.). Women's health at work. Estocolmo: Arbetslivinstitutet, 1998. p.279-307.

LEAL, O.F. Cultura reprodutiva e sexualidade. Estudos Feministas, Rio de Janeiro, IFCS/UFRJ, v.6, n.2, p.376-392, jul./dez. 1998.
MARSHALL, K. Stay-at-home dads. Perspectives on labour and income, Ottawa: Statistics Canada, v.10, n.1, p.9-15, abr./jun. 1998.

MESSING, K.; ELABIDI, D. Collaboration entre les travailleurs lors d'efforts physiques. Objectif Prévention, Montreal, v.21, n.5, p.24-26, 1998.

MESSING, K.; CHATIGNY, C.; COURVILLE, J. L'invisibilité du travail et la division léger/lourd: impact sur la santé et la securité du travail. Objectif Prévention, Montreal, v.19, n.2, p.13-16, 1996.

OLIVEIRA, M.C. A família brasileira no limiar do ano 2000. Estudos Feministas, Rio de Janeiro, IFCS/UFRJ, v.4, n.1, p.55-63, jan./ jun. 1996.

RAGO, M. Do cabaré ao lar. Uma utopia da cidade disciplinar (Brasil 1890-1930). Rio de Janeiro: Paz e Terra, 1987.

RIZEK, C.S.; LEITE, M.P. Dimensões e representações do trabalho fabril feminino. Cadernos Pagu, Campinas, Unicamp, v.10,p.281-307, 1998.

ROCHA-COUTINHO, M.L. Tecendo por trás dos panos. A mulher brasileira nas relações familiares. Rio de Janeiro: Rocco, 1994.

ROLLE, P. O que é a qualificação do trabalho? Tempo Social, Revista de Sociologia da USP, São Paulo, USP, v.1, n.2, p.83-87, jul./dez. 1989.

ROTENBERG, L. et al. Trocando o dia pela noite - uma análise do trabalho noturno sob a ótica de gênero. In: BARBOSA, R.M. et. al. (Org.). Interfaces - gênero, sexualidade e saúde reprodutiva. Campinas: Editora da Unicamp, 2002. p.389-432.

Gênero e trabalho noturno: sono, cotidiano e vivências de quem troca a noite pelo dia. Cadernos de Saúde Pública, Rio de Janeiro, ENSP/Fiocruz, v.17, n.3, p.639-649, jul.-ago. 2001.

RUTENFRANZ, J.; KNAUTH, P; FISCHER, F.M. Trabalho em turnos e noturno. São Paulo: Hucitec, 1989.

SARTI, C. A família como espelho . São Paulo: Editores Associados, 1996.

SILVA, L.H. Admitimos mulheres para trabalhos leves. Estudos Feministas, Florianópolis, UFSC, v.3, n.2, p.1-13, jul./dez. 1995.

SOARES, A. Automação, (des)qualificação e emoção nos paraísos de consumo. Cadernos Pagu, Campinas, Unicamp, v.10, p.113-146, 1998.

Se eu pudesse não ser caixa de supermercado... Estudos Feministas, Rio de Janeiro, UFRJ, v.5, n.1, p.82-102, jan./jun. 1997.

TOSCANO, M.; GOLDENBERG, M. A revolução das mulheres. Um balanço do feminismo no Brasil. Rio de Janeiro: Revan, 1992.

VÉZINA, N.; COURVILLE, J. Integration of women into traditionally masculine jobs. Women et Health, New York, Hawort Press Inc., v.18, n.3, 1992.

VOGEL, L. A Quebec contribution to a debate which Europe's unions must enter. In: MESSING, K. (Org.). Integrating gender in ergonomics analysis - strategies for transforming women's work Bruxelas: European Trade Union Technical Bureau for Health and Safety, 1999. p.9-33.

Willer Baumgartem Marcondes: Cientista Social, Pesquisador bolsista do Departamento de Ciências Sociais da Escola Nacional de Saúde Pública, Fiocruz-RJ(willerbm@ensp.fiocruz.br).

Lúcia Rotenberg: Bióloga, Pesquisadora do Departamento de Biologia do Instituto Oswaldo Cruz, Fiocruz-RJ(rotenber@ioc.fiocruz.br).

Luciana Fernandes Portela: Bióloga, Pesquisadora do Departamento de Biologia do Instituto Oswaldo Cruz, Fiocruz-RJ (lportela@ioc.fiocruz.br).

Claudia Roberta de Castro Moreno: Bióloga, Pesquisadora do Departamento de Psicobiologia da Escola Paulista de Medicina, UnifespSP (crmoreno@psicobio.epm.br). 